\title{
Comparison of platelet storage in PL146 and PL732 plastic packs: preliminary in vitro studies
}

\author{
DR EDWARDS, CC ENTWISTLE \\ From the Regional Blood Transfusion Centre, John Radcliffe Hospital, Headington, Oxford
}

SUMMARY This paper is a preliminary report of in vitro studies comparing platelet storage in the new polyolefin PL732 packs with the present polyvinyl PL146 packs. The parameters used to assess platelet viability in these studies were the recovery from the hypotonic stress test (HST) and the $\mathrm{pH}$. The effect of the mass of the concentrate was assessed by preparing $20 \mathrm{~g}, 35 \mathrm{~g}$ and $50 \mathrm{~g}$ packs. The method of agitation was tested comparing a vertical rotator with a flat-bed, rocking agitator.

In all the subgroups the PL732 packs fared better than the PL146 packs in terms of HST recovery and $\mathrm{pH}$. The $35 \mathrm{~g}$ and $50 \mathrm{~g}$ packs were statistically inseparable but the $20 \mathrm{~g}$ packs were significantly worse both in PL732 and PL146. The vertical rotator augmented the beneficial effects of the PL732 plastic especially in terms of $\mathrm{pH}$. The $35 \mathrm{~g}$ and $50 \mathrm{~g}$ packs in PL732 on a vertical rotator gave results after 5 days storage at $22^{\circ} \mathrm{C}$ which were vastly superior $(\mathrm{p} \leqslant 0.001)$ to the $35 \mathrm{~g}$ and $50 \mathrm{~g}$ packs in PL146 after only three days storage. Thus it would appear that the use of PL 732 packs might enable the storage life of platelet concentrates to be increased to five days. Further in vivo studies are to be undertaken to ensure these in vitro improvements benefit the patient.

Platelet concentrates stored in conventional polyvinyl packs (PL146 Travenol), have a shelf-life of two to three days at $22^{\circ} \mathrm{C}$. After this time the accumulation of $\mathrm{CO}_{2}$ and lactate cause the $\mathrm{pH}$ to fall below 6.0 with disastrous effects on platelet viability. ${ }^{1-4}$ Improvement of gaseous exchange between the concentrates and the atmosphere should delay accumulation of $\mathrm{CO}_{2}$ and prolong storage life. Garber described a polyolefin pack (PL732 Travenol) which showed improved gaseous permeability when compared with the PL146 pack $^{5}$ and work by Murphy and $\mathrm{Holme}^{6}$ suggested improved platelet viability both in vitro and in vivo.

To substantiate these suggestions a three-centre trial was begun involving the Transfusion Centres of Dublin, Manchester and Oxford, each working independently. The first stage of this trial was to confirm the in vitro characteristics of the PL732 packs. This paper reports the findings at the Oxford Centre.

\section{Material and methods}

Whole blood was drawn from 84 healthy donors who had not taken aspirin in the past seven days. Care was taken to ensure a clean venepuncture. All packs were

Accepted for publication 5 May 1982 supplied by Travenol Laboratories Ltd, Thetford, Norfolk. Triple packs were used, the primary pack being of PL146 and containing CPD anticoagulant. Forty-two packs had conventional satellites of PL146 plastic and 42 had satellites of PL732 for the storage of platelets. All concentrates were prepared at room temperature within two hours of collection.

The initial centrifugation to prepare platelet-rich plasma (PRP) was at $1000 \mathrm{~g}$ for $7 \mathrm{~min}$. A weighed 180 $\mathrm{g}$ of PRP was transferred to the satellite pack giving a mean yield of $79 \pm 18 \%$ of the available platelets. A second centrifugation at $2100 \mathrm{~g}$ for $20 \mathrm{~min}$ produced platelet-poor plasma (PPP) and a button of platelets. Weighed amounts of PPP were transferred to the second satellite using a plasma-extractor (Fenwal BM1) and a spring-balance (Salter) to leave $20 \mathrm{~g}, 35 \mathrm{~g}$ and $50 \mathrm{~g}$ amounts in which to resuspend the platelets. The weights of the concentrates were subsequently checked and all the packs were found to be within $3 \mathrm{~g}$ of their desired weight. The platelets were left undisturbed at room temperature for at least $90 \mathrm{~min}$ before re-suspension.

STORAGE

All concentrates were stored in a $22^{\circ} \mathrm{C}$ incubator (Termacks). Because of reports that the method of agitation might influence viability' (also S Murphy, personal communication, 1981), equal numbers of 
packs were stored on either: (i) a vertical rotator (Helmer PA4) with each pack separate and turning at $5 \mathrm{rpm}$ or (ii) a rocking flat-bed agitator (Luckhams) in batches of 4-6 and moving at 25 oscillations/min.

DETERMINATION OF pH

This was measured on the $\mathrm{pH}$ electrode of an ABL2 blood-gas analyser.

\section{DETERMINATION OF CONCENTRATION OF} PLATELETS

This was derived from the platelet count of a Coulter S Plus II.

\section{DETERMINATION OF HYPOTONIC STRESS TEST} (HST)

The method described by Handin et $a l^{8}$ was modified as follows: a Pye Unicam SP 8100 recording spectrophotometer was used with the wavelength set at $610 \mu \mathrm{m}$ and zeroed for absorbance on a cuvette of distilled water. Full-scale deflection was set at 0.500 optical density units (ODU) and the trace recorded at $100 \mathrm{~s} / \mathrm{cm}$. The distilled water was used as a blank in the second channel during the tests: $0.3 \mathrm{ml}$ of distilled water was rapidly added to $0.6 \mathrm{ml}$ of platelet concentrate and the changes in optical density in ODU were recorded for the next $5 \mathrm{~min}$. The usual pattern was a rapid fall in optical density followed by a recovery. The degree of recovery has been shown to be a function of platelet viability.

SAMPLING

All samples from a given pack were taken through a self-sealing entry port (Travenol C2405). Care was taken to avoid contamination and all packs were subsequently shown to be sterile after five days by routine bacteriological plating and culture. Sample size was kept to $1.2 \mathrm{ml}$ in order to avoid excessive loss of platelets during the experiments.

\section{Results}

The 84 packs were tested under varying conditions of pack material, method of agitation and weight of $\overrightarrow{0}$ concentrate. This gave rise to 12 subgroups with seven samples in each. Occasional concentrates were found to have very high or very low yields which were atypical for their group and on testing gave results that were outside the $95 \%$ confidence limits. Five such outliers were excluded from further analysis and none of the 12 groups contained more than one outlier.

\section{HYPNOTIC STRESS TEST (HST)}

Preliminary experiments showed that the recovery from the lowest recorded optical density to the fiveminute point was reproducible to within $\pm 0 \cdot 001$ ODU for a given pack on a given day. As this series compares packs with different concentrations it was decided to follow the practice of Kim and Baldinis calling the recovery in ODU on a day nought 100 and expressing subsequent results as a percentage this value. Figs 1 and 2 show little difference between the three weights of concentrate in PL146 whichever method of agitation is used. The $20 \mathrm{~g}$ concentrates in PL732 show a similar pattern but the $35 \mathrm{~g}$ and $50 \mathrm{~g}$ packs in PL732 show a marked improvement in recovery both on day three and day five. Analysis of

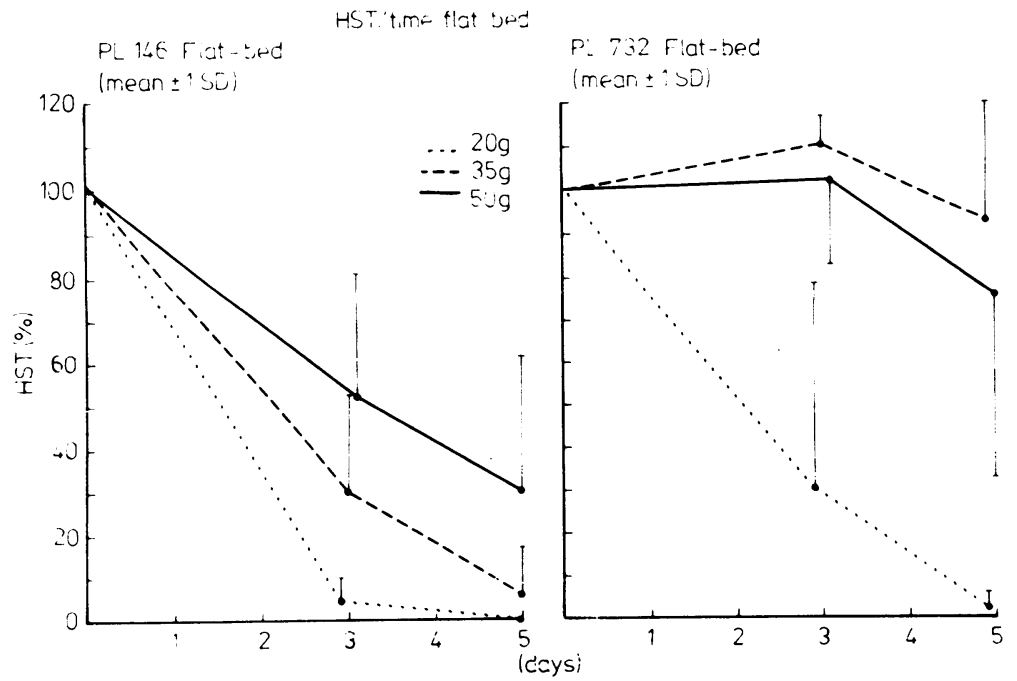

Fig. 1 Hypotonic stress recovery (mean \pm ISD) of packs in PLI46 and PL732 on a Flat-Bed Agitator 


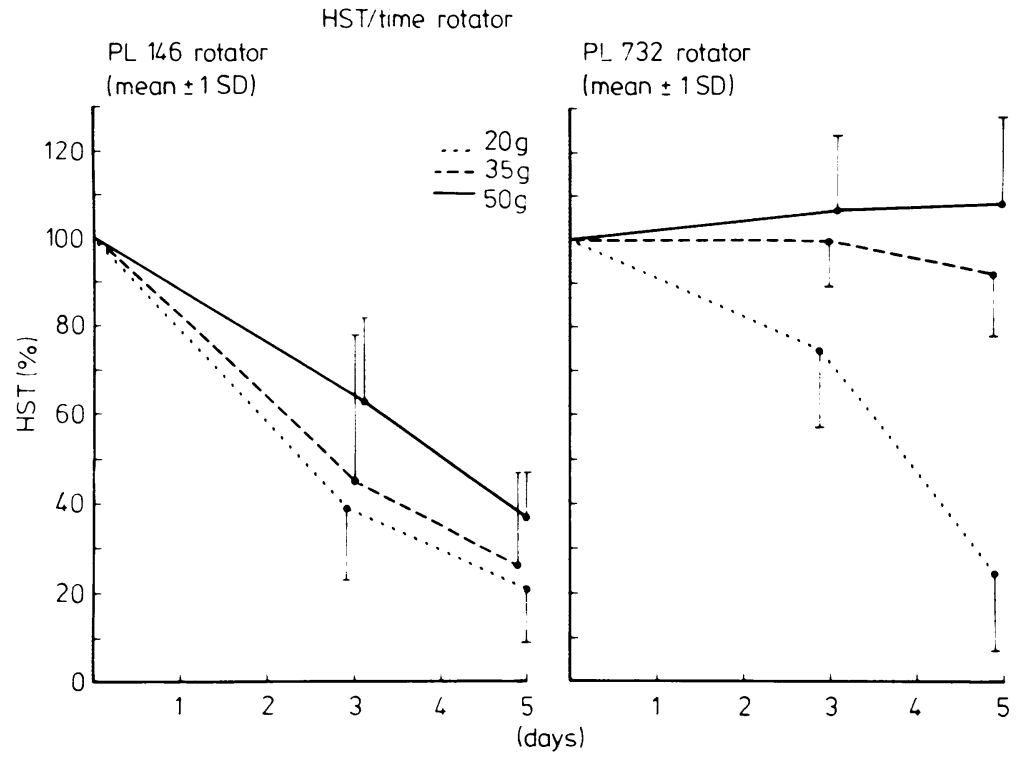

Fig. 2 Hypotonic stress recovery (mean $\pm 1 S D$ ) of packs in PLI46 and PL732 on a Rotator

the $35 \mathrm{~g}$ and $50 \mathrm{~g}$ packs as a whole (Fig 3 and Table 1) reveals a significantly better recovery of platelets in PL732 both on days three and five compared to the day three recovery in PL146. Statistically $p$ is always $<0.01$ and often $<0.001$. The difference between the day five values in PL732 was uninfluenced by the method of agitation $(p>0 \cdot 1)$.

$\mathrm{pH}$

The $\mathrm{pH}$ shows a broadly similar pattern to the HST

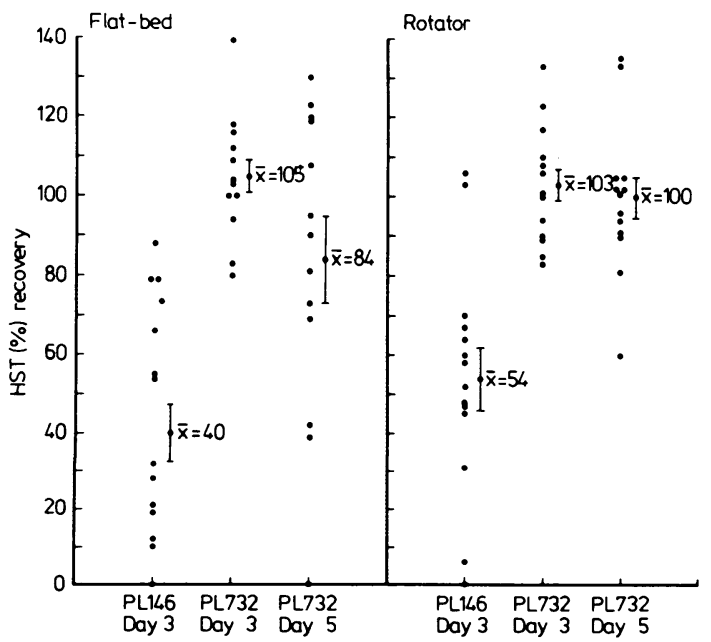

Fig. 3 Pooled results of HST recovery in $35 \mathrm{~g}$ and $50 \mathrm{~g}$ packs (mean $\pm I S E$ ) comparing day 3 in PL146 with days 3 and 5 in PL732 on both Flat-Bed and Rotator results. Again there is little difference between the three PL146 concentrates and the $20 \mathrm{~g}$ PL732 concentrates but the $35 \mathrm{~g}$ and $50 \mathrm{~g}$ PL732 concentrates show improved maintenance of $\mathrm{pH}$. This difference is more marked when the platelets are stored on a rotator (Figs. 4, 5, 6 and Table 2). Under these circumstances the $35 \mathrm{~g}$ and $50 \mathrm{~g}$ packs show a rise in $\mathrm{pH}$ on day three.

\section{Comment}

The in vitro parameters used in this study show that PL732 is significantly better than PL146 for storing platelets, provided there is an adequate volume of concentrate. The $20 \mathrm{~g}$ pack of PL732 fared no better

Table 1 Values for $p$ derived from Fig. 3 showing the difference between day 3 in PL146 and days 3 and 5 in PL732 in terms of HST recovery. (Pooled $35 \mathrm{~g}$ and $50 \mathrm{~g}$ packs)

\begin{tabular}{llll}
\hline Flat-Bed & & & \\
\hline & PL146 & PL732 & $p$ \\
\hline $\begin{array}{l}\text { Day } \\
\text { Day }\end{array}$ & 3 & 3 & $\leqslant 0.001$ \\
Rotator & 3 & 5 & $\leqslant 0.01$ \\
\hline $\begin{array}{l}\text { Day } \\
\text { Day }\end{array}$ & 3 & 3 & \\
\hline
\end{tabular}

PL146 FB Day 3: PL732 Rotator Day $5 p \leqslant 0.001$ PL732 FB Day 5: PL732 Rotator Day $5 \mathrm{p}>0 \cdot 1$ 


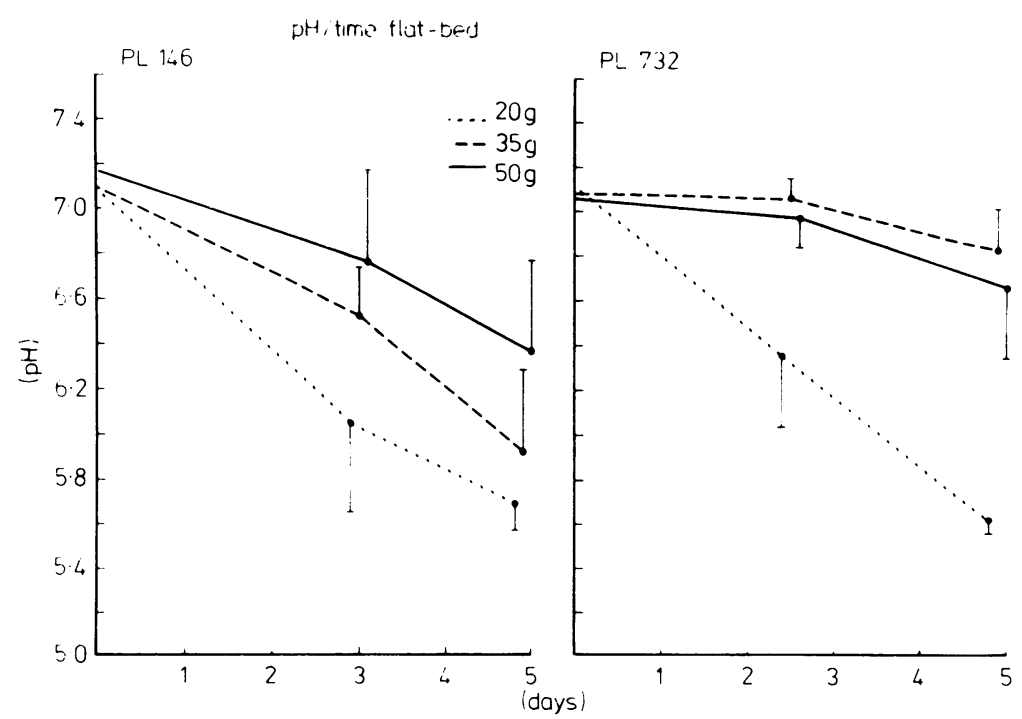

Fig. 4 pH change (mean \pm ISD) of packs in PL146 and PL732 on a Flat-Bed Agitator

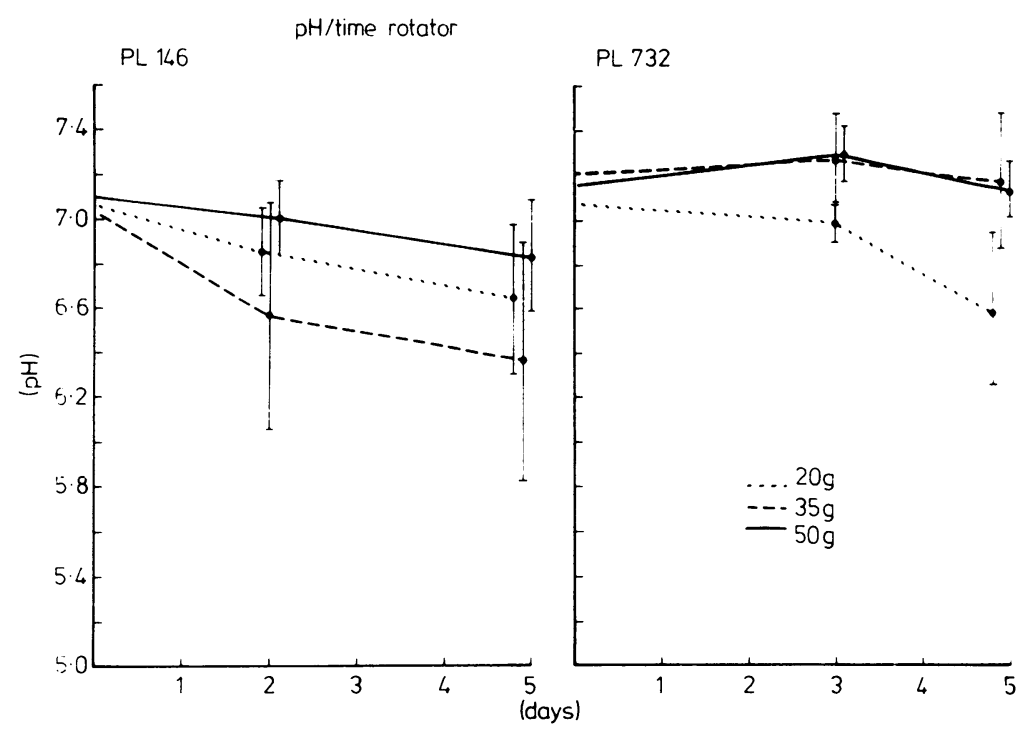

Fig. 5 pH change (mean \pm ISD) of packs in PL146 and PL732 on a Rotator

than the PL146 packs and in general the $20 \mathrm{~g}$ packs were useless by day five. In marked contrast the $35 \mathrm{~g}$ and $50 \mathrm{~g}$ concentrates in PL732 were significantly better than their counterparts in PL146, whether on a flat-bed or a rotator.

The improvement was most marked in terms of the HST. Platelet response in the HST was shown to correlate with the in vivo post-transfusion recovery by Valerie et $a l^{10}$ and with viability by $\mathrm{Kim}$ and Baldini. ${ }^{9}$ A combination of PL732 and rotator gave recoveries at day five which were a little different from day 0 values and very much better $(p<0.001)$ than the day three recoveries in PL146.

The differences in $\mathrm{pH}$ were not so well marked and indeed the day five values in PL732 on a flat-bed were not significantly better than the day three values in PL146. The rotator maintained $\mathrm{pH}$ better than the flat-bed in all groups, though the improvement was most marked in the PL732 packs. The day five values in PL732 on a rotator were much better than the day 


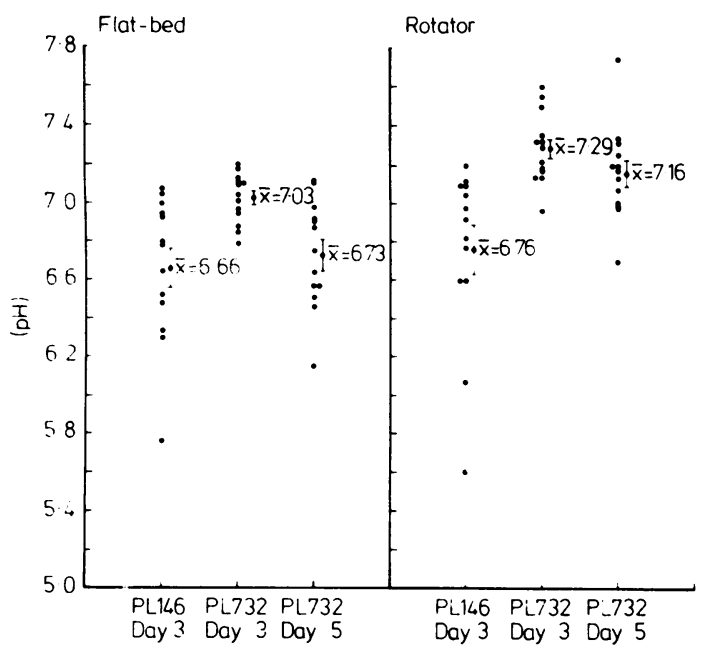

Fig. 6 Pooled results of $\mathrm{pH}$ values in $35 \mathrm{~g}$ and $50 \mathrm{~g}$ packs (mean $\pm 1 S E$ ) comparing day 3 in PL146 with days 3 and 5 in PL732 on both Flat-Bed and Rotator

Table 2 Values for $p$ derived from Fig. 6 showing the difference between day 3 in PL 146 and days 3 and 5 in PL732 in terms of $\mathrm{pH}$ (pooled $35 \mathrm{~g}$ and $50 \mathrm{~g}$ packs)

\begin{tabular}{llll}
\hline Flat-Bed & & & \\
\hline & PL146 & PL732 & $P$ \\
\hline $\begin{array}{l}\text { Day } \\
\text { Day } \\
\text { Rotator }\end{array}$ & 3 & 3 & $\leqslant 0 \cdot 002$ \\
\hline $\begin{array}{l}\text { Day } \\
\text { Day }\end{array}$ & 3 & 5 & $>0 \cdot 1$ (NS) \\
\hline
\end{tabular}

PL146 FB Day 3: PL732 Rotator Day $5 p \leqslant 0.001$

PL732 FB Day 5: PL732 Rotator Day $5 p>0 \cdot 1$

five values in PL732 on a flat-bed $(p<0.001)$. Thus it would appear that the rotator helps to maintain the $\mathrm{pH}$, but this is not the sole reason for the improvement in HST seen in the PL732 packs. Further studies looking at the platelet morphology and gaseous exchange will be reported in subsequent papers.

Obviously in vivo studies are necessary to show that these in vitro improvements benefit the patient. These form the basis of the later part of this trial and will be reported in due course. With the parameters so far investigated it would appear that five days storage in PL732 is less detrimental to platelets than three days in a conventional PL146 pack. The use of the rotating agitator gives the additional benefit of a more physiological $\mathrm{pH}$ for transfusion. However both these benefits may be lost if the volume of concentrate is too small. Regulation of volume to about $40 \mathrm{ml}$ seems sensible and a calculation of the weight of pack contents is an easy way to achieve this.

We are grateful to Dr T Peto, Nuffield Department of Medicine for statistical advice, to the laboratory staff of the Haematology Department John Radcliffe Hospital for assistance, to Dr A Fisher for use of $\mathrm{pH}$ meter and other facilities, and to Dr AA Sharp of the Haematology Department and Mr A Hunt Principal Scientific Officer, Blood Transfusion Centre for advice and encouragement.

\section{References}

' Murphy S, Sayer SN, Gardner FH. Storage of platelet concentrates at $22^{\circ} \mathrm{C}$. Blood 1970;35:549.

${ }^{2}$ Murphy S, Gardner FG. Platelet storage at $22^{\circ} \mathrm{C}$; role of gas transport across plastic containers in maintenance of viability. Blood 1975;46:209.

${ }^{3}$ Rock G, Figuerdo A. Metabolic changes during platelet storage. Transfusion 1976;16:571.

4 Slichter SJ, Harker LA. Preparation and storage of platelet concentrates. II Storage variables influencing platelet viability and function. $\mathrm{Br} J$ Haematol 1976;34:403.

5 Garber JW. New plastics development: report of symposium. Further developments in transfusion practice. Cambridge, 1980:1-9.

- Murphy S, Holme S. Improved platelet preservation in a new container. Washington: Abstracts of 33rd Annual Meeting of American Association of Blood Banks, 12.

${ }^{7}$ Holme S, Vaidja K, Murphy S. Platelet storage at $22^{\circ} \mathrm{C}$ : effect of type of agitation on morphology, viability and function in vitro. Blood 1978;52:425.

${ }^{8}$ Handin RI, Fortier NL, Valerie CR. Platelet response to hypotonic stress after storage at $4^{\circ} \mathrm{C}$ or $22^{\circ} \mathrm{C}$. Transfusion 1970;10:305.

' Kim BK, Baldini MG. The platelet response to hypotonic shock; its value as an indicator of platelet viability after storage. Transfusion 1974;14:130.

10 Valerie CR, Feingold H, Marchionni LD. The relation between response to hypotonic stress and ${ }^{51} \mathrm{Cr}$ recovery in vivo of preserved platelets. Transfusion 1974;14:331.

Requests for reprints to: Dr DR Edwards, Ysbyty Glan Clwyd, Bodelwyddan, Nr Rhyl, Clwyd, N Wales LL18 5UJ. 